\title{
Preface and Acknowledgments
}

Much of the challenge of putting together a volume of this kind comes from the fact that the sources date from another era, are the product of another culture, and were written in another language than our own. These overlays of difference are what make the life stories of nineteenthcentury French workers both intriguing and instructive. They also raise continual questions about the meaning these authors intended to convey and about what sense we, as inhabitants of another place and time, are able to make of their words.

Fortunately, the task of translation is made easier by the fact that these worker-authors relate their stories with few stylistic pretensions. Still, as spare and simple as their prose may be, there are a few conventions that are likely to prove discordant to the modern ear. The tendency to repeat key words, phrases, and even whole incidents (most apparent in the texts by Bédé and Truquin) is at times reminiscent of the use of the refrain in popular songs or poems. I have tried to omit redundant passages, particularly when they seemed to interrupt the flow of the narrative, without eliminating altogether an element of style that suggests how closely the writing of working-class authors remained tied to an essentially oral tradition.

My most difficult task has been to pare down the stories so as to keep this anthology to a manageable length. This required cutting out a great deal of valuable material, sometimes at the expense of the continuity of the author's narrative. In deciding what to exclude, I have been guided by a desire to give this collection a clear focus on the everyday activities, work life, and popular politics of the nineteenth-century working class. The result is, however, a very personalized selection, and by no means the only one that could be made. Wherever possible, my practice has been to 
remove whole passages rather than separate snippets. To ensure that the reader would know whenever something has been removed, I have marked the spot by inserting ellipsis points in brackets, thus: [ . . ]. When the excised passage was substantial, I have sometimes inserted a summary of what it contained.

Problems of a more concrete nature arose in translating specialized vocabulary, such as the popular slang or the occupational cant of the nineteenth century. When comment seemed called for, I have usually indicated the French term and added a brief explanatory note. More frequently, I have used footnotes to clarify or contextualize statements in the texts. I see this volume as serving the needs of a mixed audience with widely varying familiarity with French history and culture; however, the notes are aimed at a reader with limited background.

Certain of these authors were in the habit of italicizing words or phrases, presumably for emphasis, though their choices sometimes make little sense to the contemporary reader. I have retained the authors' italics, except in a few cases where they seemed confusing or distracting. I have felt free to make other minor changes to the text to clarify its meaning; for example, I have sometimes added missing punctuation or placed in separate paragraphs the statements and rejoinders in a conversation that are run together in the French.

In attempting to interpret the authors' words, I have often found my own knowledge of the culture, period, and language insufficient, and have turned to others more expert than myself for assistance and advice. In the process, I have contracted a heavy debt to a number of people which I would like to take this opportunity to acknowledge.

Four individuals stand out for the special contributions they have made over a period of several years. First, I have Victoria Bonnell to thank for initially encouraging me to undertake this work, knowing from her own experience with this anthology's companion volume, The Russian Worker, that the fascination of the material would draw me in.

Over a five-year period, my editor Sheila Levine provided the practical guidance that made it possible for this project to see completion. Her sure hand as well as her patience and flexibility when it came to deadlines-but above all her willingness to respect what I saw as the larger purpose such a book might serve-never wavered.

Jonathan Beecher has always made me the gift of his vast knowledge of and enthusiasm for French history. I could ask for no more helpful or supportive colleague.

Finally, Susanna Barrows's insight into French popular culture (to say nothing of her mastery of colloquial speech and gesture!) has been a 
constant source of amazement and delight, whether I was trying to puzzle out the meaning of some tantalizingly ambiguous passage in these memoirs or grappling with the many-layered meanings of the social interactions typical of the working-class café.

There is a much larger group of individuals who have made material contributions to this project, and though I cannot mention them all, I wish at least to acknowledge the combination of kind words of encouragement and the no less valued-and well-deserved-critical appraisals, both of the translations and of the introduction, that I received from Mary Jo Maynes, Bill Reddy, Bill Sewell, George Sheridan, Chuck Tilly, the members of the Berkeley History Seminar, and the anonymous reviewers of this project at its various stages of completion.

What began for me as a casual foray into a new way of looking at the nineteenth century grew to become a long-term project. It has taken far longer than I originally anticipated, and it is with a certain relief that I am able to bring it to a conclusion. Yet there is a small twinge of regret as well, for never again do I expect to work with materials in which the presence and individuality of the authors is as vividly defined as in the stories told in these pages. 
